\title{
HUBUNGAN PENGETAHUAN IBU DENGAN PEMBERIAN ASI EKSKLUSIF USIA > 6-12 BULAN DI KECAMATAN TALANGO KABUPATEN SUMENEP
}

Sri Sumarni, Program Studi IImu Keperawatan UNIJA Sumenep

e-mail: sri.sumarni73@yahoo.co.id

Nelyta Oktavianisya, Program Studi Profesi Ners UNIJA Sumenep

e-mail: nelyta2516@gmail.com

\section{ABSTRACT}

The first and main food for babies is breast milk (ASI). Breast milk contains the most complete nutritional composition and ideal for the growth and development of infants during the first 6 months. The percentage of coverage of exclusive breastfeeding in Sumenep in 2011-2013 decreased but increased in 2014 (45.5\%) but has yet to reach the target (80\%). Coverage rate of exclusive breastfeeding in the District Talango any decline of the Year The year 2012-2014 is still far from the target attainment (80\%). This study aims to determine the relationship between knowledge of mothers exclusively breastfeeding infants aged> 6-12 months.

This research is analytic survey with cross sectional approach. The number of samples in this study were as many as 38 nursing mothers who have infants aged> 6-12 months in the working area of Puskesmas (Health Center) Talango sub-district Talango taken using proportionate random sampling technique. Collecting data through interviews using a questionnaire. The statistical test used to analyze the relationship between variables using chi square.

The results showed that most respondents (55.3\%) had good knowledge and $60.5 \%$ of respondents who breastfed exclusively. The results of data analysis showed a significant relationship between knowledge and exclusive breastfeeding $(p=0.028)$.

Efforts to improve the implementation of exclusive breastfeeding for infants aged> 6-12 months through empowerment to health workers, such as by an increase in personnel and skills in order to increase the use of breast milk.

Keywords: Knowledge mother, exclusive breastfeeding, age $>$ 6-12

\section{PENDAHULUAN}

Indikator utama derajat kesehatan masyarakat adalah angka kematian bayi (AKB) atau Infant Mortality Rate (IMR). Dari hasil penelitian yang ada, angka kematian ini tidak berdiri sendiri, melainkan terkait dengan faktorfaktor lain, terutama gizi. Bayi atau anak balita yang kekurangan gizi sangat rentan terhadap penyakit-penyakit infeksi, termasuk diare dan infeksi saluran akut, utamanya pneumonia. Gizi untuk bayi yang paling sempurna dan yang paling murah bagi bayi adalah air susu ibu (ASI). Manfaat ASI saat ini sudah tidak diragukan lagi dan pemerintah juga menggalakkan pemberian ASI secara Eksklusif (Notoatmodjo P. D., 2011).

Pemberian ASI secara Eksklusif selama 6 bulan merupakan makanan terbaik bagi bayi, akan tetapi dalam pelaksanaannya banyak kendala yang muncul, antara lain ibu kurang memahami tata laksana laktasi yang benar, produksi ASI kurang, bayi terlanjur

mendapatkan prelacteal feeding (air gula atau formula) pada hari pertama kelahiran, kelainan puting ibu, kesulitan bayi dalam menghisap, ibu hamil lagi saat masih menyusui, ibu bekerja sehingga harus meninggalkan bayinya di rumah, keinginan untuk disebut modern, dan pengaruh iklan susu formula yang kian gencar (Partiwi, 2009).

Menurut Notoatmodjo (2003) mengatakan bahwa pendidikan seseorang berhubungan dengan kehidupan sosialnya. Semakin tinggi pendidikan seseorang maka ia akan lebih memperhatikan masalah kesehatannya. Oleh sebab itu, ibu dengan pendidikan tinggi akan cenderung memiliki pengetahuan yang baik tentang ASI Eksklusif, dan sebaliknya ibu yang memiliki pendidikan rendah cenderung sulit untuk menyerap informasi khususnya pengetahuan tentang ASI Eksklusif sehingga menyebabkan sikap tidak perduli terhadap program kesehatan. 
Data WHO menunjukan pada Tahun 2012, pemberian ASI Eksklusif baru $37 \%$ dan baru terpenuhi 26 negara (Pramesti, 2012). Sementara di negara berkembang hanya 39\% ibu-ibu yang memberikan ASI eksklusif (UNICEF, 2011). Berdasarkan data secara nasional cakupan pemberian ASI Eksklusif 0-6 bulan di Indonesia berfluktuasi dalam empat tahun terakhir, menurut data Susenas tahun Tabel 1 Cakupan ASI Eksklusif

\begin{tabular}{|c|c|c|c|c|c|}
\hline Pencapaian ASI Eksklusif & 2011 & 2012 & 2013 & 2014 & Target \\
\hline Jawa Timur & $61,52 \%$ & $64,08 \%$ & $68,3 \%$ & $0 \%$ & $80 \%$ \\
\hline Kabupaten Sumenep & $11,9 \%$ & $17,1 \%$ & $18,1 \%$ & $45,5 \%$ & $80 \%$ \\
\hline Kecamatan Talango & $0 \%$ & $10,8 \%$ & $3,0 \%$ & $2,1 \%$ & $80 \%$ \\
\hline
\end{tabular}

Berdasarkan Tabel 1. Angka Cakupan ASI Eksklusif di provinsi Jawa Timur mengalami peningkatan dalam 3 tahun terakhir tetapi masih belum mencapai target yang diharapkan yaitu sebesar (80\%). Sedangkan cakupan ASI Eksklusif di Kabupaten Sumenep tahun 20112013 terjadi penurunan namun meningkat di tahun $2014(45,5 \%)$ tetapi masih belum mencapai target (80\%). Angka cakupan ASI Eksklusif di Kecamatan Talango setiap Tahunnya terjadi penurunan dari Tahun 20122014 masih jauh dari target pencapaian (80\%).

Tabel 2 Cakupan Pemberian ASI Eksklusif di Puskesmas Kecamatan Talango Kabupaten Sumenep Tahun 2014.

\begin{tabular}{lccc}
\hline Nama Desa & $\begin{array}{c}\text { Jumlah } \\
\text { Bayi } \\
\text { Diperiksa }\end{array}$ & \multicolumn{2}{c}{$\begin{array}{c}\text { EKSKLUSIF } \\
\text { (E6) }\end{array}$} \\
\hline Talango & 33 & 0 & 0,0 \\
Gapura & 38 & 0 & 0,0 \\
Palasa & 26 & 0 & 0,0 \\
Poteran & 29 & 0 & 0,0 \\
Kombang & 23 & 0 & 0,0 \\
Essang & 25 & 0 & 0,0 \\
Cabbiya & 30 & 0 & 0,0 \\
Padike & 30 & 5 & 16,7 \\
Puskesmas & 234 & 5 & 2,1 \\
\hline
\end{tabular}

Berdasarkan Tabel 2 Cakupan pemberian ASI Eksklusif pada tahun 2014 dari 8 desa yang berada di wilayah kerja UPT. Puskesmas Talango Kecamatan Talango masih sangat rendah, ibu yang masih memberikan ASI Eksklusif pada anaknya hanya ada 1 desa yaitu desa Padike dengan nilai presentase $16,7 \%$. Jadi masalah dalam penelitian ini rendahnya pencapaian pemberian ASI Eksklusif diwilayah kerja puskesmas Talango Kecamatan Talango tahun 2014 yaitu 2,1\% dari target yang seharusnya $80 \%$.
2011 angka cakupan ASI E ksklusif naik menjadi 42\% dan menurut SDKI tahun 2012 cakupan ASI Eksklusif sebesar 27\%. Menurut Data Riset Kesehatan Dasar (Riskesdas) 2013, angka pemberian ASI eksklusif pada bayi berumur 6 bulan hanya mencapai angka 30,2\%. Data capaian pemberian ASI Eksklusif tersebut masih belum memenuhi target yang

diharapkan yaitu sebesar (80\%).

Banyak faktor yang mempengaruhi
rendahnya pemberian ASI Eksklusif, dipengaruhi oleh faktor internal dan faktor eksternal. Faktor internal diantaranya pendidikan yang rendah, pengetahuan, sikap atau perilaku, psikologis, fisik ibu, emosional, dan faktor eksternal diantaranya peran suami, sosial budaya, kurangnya petugas kesehatan, meningkatnya promosi susu kaleng sebagai pengganti ASI, pemberian informasi yang salah. Tingkat pengetahuan sangat berpengaruh terhadap pemberian ASI Eksklusif. Sebagian masyarakat di masih banyak yang belum mengerti tentang ASI Eksklusif.

Berdasarkan studi pendahuluan dapat disimpulkan bahwa pencapaian ASI Eksklusif di UPT. Puskesmas Kecamatan Talango Kabupaten Sumenep terjadi penurunan dalam pemberian ASI Eksklusif dan masih jauh dari target $(80 \%)$, jadi peneliti tertarik untuk melakukan penelitian tentang hubungan pengetahuan ibu dengan pemberian ASI Eksklusif Usia > 6-12 bulan di Kecamatan Talango Kabupaten Sumenep"

\section{METODE PENELITIAN}

Penelitian ini merupakan penelitian survei analitik dengan pendekatan Cross Sectional. Penelitian ini bertujuan untuk mencari hubungan antara pengetahuan ibu sebagai variabel bebas (independen) dengan pemberian ASI eksklusif sebagai variabel terikat (dependen) yang masing-masing datanya dikumpulkan dalam satu waktu yang sama. 
Populasi dalam penelitian ini adalah semua ibu yang mempunyai bayi usia $>6-12$ bulan di Kecamatan Talango sebanyak 234 orang, berdasarkan data terakhir Puskesmas Kecamatan Talango bulan Desember tahun 2015. Sampel dalam penelitian ini adalah sebagian ibu yang mempunyai bayi usia $>6-12$ bulan di Kecamatan Talango Kabupaten Sumenep sebanyak 38 orang. Tekhnik sampling berdasarkan proportionate random sampling dan diperoleh jumlah sampel sebanyak 38. Pengumpulan data primer diperoleh melalui wawancara dengan menggunakan kuesioner dan dukumentasi. Data sekunder yangdiperoleh dari Dinas Kesehatan Kabupaten Sumenep, Puskesmas, dan Bidan adalah data ibu menyusui. Analisis data menggunakan analisis univariat danbivariatuji chi-square kemaknaan sebesar $5 \%(\alpha=0,05)$ (Notoatmodjo, 2010).

\section{HASIL PENELITIAN}

Responden penelitian ini berjumlah 38 . Sebaran karakteristik responden menurut umur ibu, pendidikan ibu, umur bayi, jenis kelamin bayi, pengetahuan ibu, dan pemberian ASI Eksklusifdapat dilihat pada Tabel 3.

Tabel 3 Distribusi Karakteristik Responden

\begin{tabular}{llc}
\hline Karakteristik Responden & $\mathrm{n}$ & $\%$ \\
\hline Umur Ibu (Tahun) & & \\
$24-31$ & 25 & 65,79 \\
$20-35$ & 13 & 34,21 \\
\hline
\end{tabular}

\begin{tabular}{|c|c|c|}
\hline \multicolumn{3}{|c|}{ Pendidikan Ibu } \\
\hline SMP & 5 & 7,35 \\
\hline SMA & 47 & 69,12 \\
\hline \multicolumn{3}{|c|}{ Umur Bayi (Bulan) } \\
\hline 7 Bulan & 11 & 28,95 \\
\hline 8 Bulan & 9 & 23,68 \\
\hline 9 Bulan & 7 & 18,42 \\
\hline 10 Bulan & 4 & 10,53 \\
\hline 11 Bulan & 5 & 13,16 \\
\hline 12 Bulan & 2 & 5,26 \\
\hline \multicolumn{3}{|c|}{ Jenis Kelamin Bayi } \\
\hline Laki-laki & 18 & 47,37 \\
\hline Perempuan & 20 & 52,63 \\
\hline \multicolumn{3}{|c|}{ Pengetahuan Ibu } \\
\hline Baik & 21 & 55,3 \\
\hline Kurang Baik & 17 & 44,7 \\
\hline \multicolumn{3}{|c|}{ Pemberian ASI Ekslusif } \\
\hline Eksklusif & 23 & 60,5 \\
\hline Noneksklusif & 15 & 39,5 \\
\hline
\end{tabular}

Berdasarkan tabel 3.dapat dilihat bahwa umur responden antara 24 sampai 31 tahun sebanyak 25 orang $(65,79 \%)$, sedangkan umur responden antara 32 sampai 39 tahun sebanyak 13 orang $(34,21 \%)$. Sebagian besar responden berpendidikan SMA dengan prosentase sebesar 92,1\% (sebanyak 35 responden). Umur bayi yang paling banyak yaitu berumur 7 dan 8 bulan dengan prosentase masing-masing $28,95 \%$ dan $23,68 \%$. Jenis kelamin bayi adalah laki-laki sebanyak 18 bayi $(47,37 \%)$ dan perempuan 20 bayi $(52,63 \%)$. responden dengan pengetahuan baik berjumlah 21 orang (55,3\%), pengetahuan kurang baik sebanyak 17 orang (44,7\%). Responden yang memberi ASI eksklusif sebanyak 23 orang $(60,5 \%)$ dan yang tidak memberikan ASI eksklusif sebanyak 15 orang $(39,5 \%)$

Tabel 4. Hasil Uji Hubungan Pengetahuan Ibu dengan Pemberian ASI Eksklusif usia $>$ 6-12 bulan di Kecamatan Talango Kabupaten Sumenep

\begin{tabular}{|c|c|c|c|c|c|c|c|}
\hline \multirow{4}{*}{ Pengetahuan Ibu } & \multirow{2}{*}{\multicolumn{4}{|c|}{$\begin{array}{l}\text { Variabel Terikat } \\
\text { Pemberian ASI }\end{array}$}} & & & \multirow{4}{*}{$P$ value } \\
\hline & & & & & \multirow{2}{*}{\multicolumn{2}{|c|}{ Total }} & \\
\hline & \multicolumn{2}{|c|}{ Eksklusif } & \multicolumn{2}{|c|}{ Non Eksklusif } & & & \\
\hline & $n$ & $\%$ & $n$ & $\%$ & $\mathrm{~N}$ & $\%$ & \\
\hline Baik & 16 & 42,1 & 5 & 13,2 & 21 & 55,3 & 0,028 \\
\hline Kurang Baik & 7 & 18,4 & 10 & 26,3 & 17 & 44,7 & \\
\hline Total & 23 & 60,5 & 15 & 39,5 & 38 & 100 & \\
\hline
\end{tabular}

Berdasarkan tabel di atas dapat dilihat dan memberi ASI eksklusif pada bayi sebanyak bahwa responden yang mempunyai 7 orang $(18,4 \%)$, dan responden dengan pengetahuan baik dan memberikan ASI pengetahuan kurang baik tapi tidak Eksklusif pada bayi sebanyak 16 orang $(42,1 \%)$ memberikan ASI eksklusif pada bayi sebanyak dan responden dengan pengetahuan baik tetapi tidak memberikan ASI eksklusif pada bayi sebanyak 5 orang (8,3\%). Sedangkan responden dengan pengetahuan kurang baik 10 orang $(26,3 \%)$.

Berdasarkan hasil uji statistik dengan Chi square antara variabel pengetahuan ibu tentang ASI dengan variabel pemberian ASI 
eksklusif diperoleh nilai $p$ value $0,028(<0,05)$ yang artinya ada hubungan yang bermakna antara pengetahuan ibu tentang ASI dengan pemberian ASI eksklusif usia > 6-12 bulan di Kecamatan Talango Kabupaten Sumenep.

\section{PEMBAHASAN}

Berdasarkan hasil penelitian menunjukkkan bahwa ada hubungan antara pengetahuan ibu dengan pemberian ASI eksklusif usia > 6-12 bulan di Kecamatan Talango Kabupaten Sumenep dengan nilai $p$ value sebesar 0,028 . Berdasarkan hasil penelitian menunjukkan bahwa sebagian besar responden $(55,3 \%)$ dengan pengetahuan baik dan 44,7\% (17 responden) mempunyai pengetahuan kurang baik.

Hasil penelitian ini sejalan dengan teori yang menyatakan bahwa pengetahuan atau kognitif merupakan domain yang sangat penting dalam membentuk tindakan seseorang. Pengetahuan merupakan hasil dari tahu, dan ini terjadi setelah orang melakukan penginderaan terhadap suatu objek tertentu. Penginderaan terjadi melalui pancaindera manusia, yakni indera penglihatan, pendengaran, penciuman, rasa, dan raba. Sebagian besar pengetahuan manusia diperoleh melalui mata dan telinga (Notoatmodjo, 2007). Dari pengalaman dan penelitian terbukti bahwa perilaku yang didasari oleh pengetahuan lebih langgeng daripada perilaku yang tidak didasari pengetahuan (Notoatmodjo, 2003).

Hal ini sejalan pula dengan teori Green bahwa perilaku dipengaruhi oleh 3 faktor utama dimana salah satu faktor predisposisi yang ada di dalamnya terdapat pengetahuan (Notoatmodjo, 2003). Serta penelitian terdahulu yang dilakukan oleh Rahayuningsih (2005), yang menyatakan bahwa ada hubungan antara pengetahuan ibu dengan pemberian ASI eksklusif tetapi dengan tingkat keeratan yang berbeda.

\section{KESIMPULAN}

Ada hubungan yang bermakna antara pengetahuan ibu dengan pemberian ASI eksklusif usia > 6-12 bulan di Kecamatan Talango Kabupaten Sumenep.

\section{DAFTAR PUSTAKA}

Bobak, I. M., Lowdermilk, D. L., \& Jensen, M. D. (2005). Buku ajar keperawatan maternitas (Cetakan I). Jakarta: Penerbit Buku Kedokteran EGC.

Budiarti, K.D., (2011). Hubungan akupresur dengan Tingkat Nyeri dan Lama Persalinan
Kala I pada lbu Primipara di Garut. http://lontar.ui.ac.id. Diakses tanggal 1 Novenber 2013, pukul 19.14.

Danuatmaja, B., \& Meiliasari, M. (2008). Persalinan normal tanpa rasa sakit: Tidak harus sakit untuk menjadi seorang ibu (cetakan 4). Jakarta: Puspa Swara.

Eko, Ivana, Dkk. (2007). Pengaruh pemberian akupresur terhadap tingkat nyeri persalinan kala I di Rumah Sakit Rajawali Citra Potorono banguntapan Bantul 2007. Terdapat pada: http://www.skripsistikes.wordpress.com. Diakses pada : 1 November 2013 jam 16.00 WIB

Hamilton, A. (2009). Pereda nyeri dan kenyamanan dalam persalinan. Dalam $D$. M. Fraser, \& M. A. Cooper (Ed.), Myles: Buku ajar bidan. Jakarta: Penerbit Buku Kedokteran EGC.

Kuswandi, L. (2010). Melahirkan Tanpa Rasa Sakit. Terdapat pada http://www.provclinic.web.id/articles/tidak-sakit-lagi-meskimelahirkan-normal.html. Diakses pada : 3 November 2013 jam 20.00 WIB.

Mander, Rosemary. (2004). Nyeri persalinan. Alih Bahasa : Bertha sugiarto. Jakarta : EGC

Mansjoer, A dkk. (2007). Kapita Selekta Kedokteran. Jakarta: Media Aesculapius Fakultas Kedokteran UI

Marriner Tomey, Ann ., Raile Alligood, Martha. (2002). Nursing Theorist and Their Work. United State of America : Mosby Elsevier

Notoatmodjo, S. (2003). Pendidikan dan Perilaku Kesehatan. Jakarta: Rineka Cipta.

Notoatmodjo, S. (2007). Promosi Kesehatan dan IImu Perilaku. Jakarta: Rineka Cipta.

Nursalam. (2011). Konsep dan Penerapan Metodologi Penelitian IImu Keperawatan. Surabaya : Salemba Medika.

Potter, Patricia A. (2005). Buku Ajar Fundamental Keperawatan. Edisi 4. Jakarta : EGC

Rahayuningsih, Tri. (2005). Hubungan antara Pengetahuan lbu tentang ASI dengan Pemberian ASI Eksklusif di Kelurahan Purwoyoso Kecamatan Ngaliyan. Skripsi. Semarang: FIK UNNES

Situmorang, Yuniati, Dkk. (2012). Kurikulum dan modul orientasi akupresur bagi petugas puskesmas. Jakarta : Kementrian Kesehatan RI

Smeltzer, S.C and Bare B.G. (2002). Buku Ajar Keperawatan Medikal Bedah Brunner \&sudaart, vol.,ed.8. Alih Bahasa : Monica EEllen P. Jakarta : EGC 
Sukanta Putu Oka. (2003). Akupresur dan minuman untuk mengatasi gangguan

kesehatan reproduksi. PT Elex Media Komputindo,Jakarta 